\title{
Study on Improvement of Production Environmental Factors
}

\author{
Jiang Guang-Jun ${ }^{1,2,3}$ and Lv Hao-Dong, ${ }^{1, *}$
}

\author{
${ }^{1}$ College of Mechanical Engineering, Inner Mongolia University of Technology, Hohhot, 010051, China; ${ }^{2}$ Ministry of \\ Education Key Laboratory of Wind Energy and Solar Energy Utilization Technology, Hohhot, 010051, China; ${ }^{3}$ Key \\ Laboratory of Renewable Energy of Inner Mongolia, Hohhot, 010051, China
}

\begin{abstract}
With the improvement of industrial enterprises manufacturing technology advances and people's living standards, environmental issues, especially the issues of processing and manufacturing shop environment are paid more and more attention by people, and attracted the attention of the community. In order to improve the environmental quality of production workshop, taking a gear manufacturing company in Inner Mongolia for the study, analysis of human-machine gear machine shop environment by using the human factors engineering theory and methods, focusing on the microclimate environment, lighting and noise measurement and analysis. This article is based on man-machine environment theory in the field of human factors engineering, not only make qualitative and quantitative analysis on each environment factor, and analyzed the micro climate environment temperature, humidity and air velocity influence each other. Through on-site observation and measurement, acquisition of the basic parameters of environmental factors for each workshop, and the use of specialized statistical measurement data, the existing environmental provide a guarantee for situation described, then identify the crux of the problem and its reasonable improvement by contrasting the GB data, improving the productivity while ensuring the health and job security of employees.
\end{abstract}

Keywords: Data analysis and improvement, human factors engineering, people-machine-environment system.

\section{HUMAN FACTORS ENGINEERING BACKGROUND IN PRODUCTIVITY IMPROVEMENT}

Human factors engineering is a science based on the characteristics of people to improve the human-machineenvironment system [1]. In order to achieve the best match among the man-machine-environment system and improve the operating efficiency of the overall system and play to people's working potential, the human factors engineering methods and evaluation system must be utilized reasonable and efficient, thus ensuring human health, safety and comfort while increasing the productivity.

Employees work in bad shop environment is bound to affect the production efficiency, due to the economic and technical conditions, it is unrealistic to control and to improve the workshop environment effective completely, but it is necessary for the data collection and analysis in production process with unreasonable and uncoordinated phenomenon, and attain the overall improvement through global and local optimization. For the manufacturing companies, manufacturing plant environment for enterprise efficiency and employee motivation had a significant impact [1].

Through the literature review, most of the researches are limited to a single factor quantitative analysis or qualitative analysis of multiple factors, simple qualitative analysis of the specific man-machine environment factor can't in-depth study, which needs to accurately measure analysis of various factors $[1,3]$. Therefore, in order to improve the production efficiency and ensure the safety of the employees' health and work, in this study of the machine shop man-machine- environment system of the gears manufacturing companies, it will focus on the analysis of environmental factors such as micro climate, lighting and noise that have a greater impact on the shop floor systems based on the theory and method of human factor engineering and man-machine environment.

\section{REASEARCH AND ANALYSIS OF WORKSHOP MI- CRO-CLIMATE}

\section{Overview of Micro-Climate}

Air temperature, humidity, air velocity and thermal radiation are four parameters of microclimate. Staff comfortable temperature and maximum tolerable limit of the temperature range about between $10-15^{\circ} \mathrm{C}$, if the ambient temperature rises, staves will accelerate fatigue, then decrease the physical and mental efficiency. Similarly, when employees at a lower temperature environment, cardiac output will gradually increase, there will be of dull pain and lethargy, and influence on the labor efficiency [2].

\section{Status and Improvement of the Micro-Climate}

Based on the air flow rate and differences of space lighting position, we select 10 points as the measuring point in the machine shop uniformly, using N962 Wind Speed Hygrometer to measure at each point of the temperature, relative humidity and air velocity, than record these data in Table 1 below after twice consecutive measurements. In order to ensure the accuracy of the measurement, require two min- 
Table 1. The raw measurement data of microclimate environment.

\begin{tabular}{|c|c|c|c|c|c|c|}
\hline 1 & First & 16.4 & First & 28.5 & First & 0.01 \\
\hline \multirow{2}{*}{2} & First & 16.3 & First & 29.2 & First & 0.03 \\
\hline & Second & 15.9 & Second & 29.7 & Second & 0.02 \\
\hline 3 & Second & 15.9 & Second & 29.4 & Second & 0.03 \\
\hline \multirow{2}{*}{4} & First & 16.0 & First & 29.5 & First & 0.02 \\
\hline & Second & 15.9 & Second & 29.1 & Second & 0.02 \\
\hline 6 & Second & 16.0 & Second & 29.1 & Second & 0.02 \\
\hline \multirow{2}{*}{7} & First & 16.0 & First & 30.1 & First & 0.01 \\
\hline & Second & 15.9 & Second & 29.9 & Second & 0.02 \\
\hline \multirow{2}{*}{8} & First & 16.0 & First & 29.9 & First & 0.02 \\
\hline & Second & 15.9 & Second & 30.1 & Second & 0.01 \\
\hline \multirow{2}{*}{9} & First & 16.0 & First & 29.9 & First & 0.01 \\
\hline & Second & 15.9 & Second & 29.9 & Second & 0.02 \\
\hline
\end{tabular}

utes before measuring the temperature in air velocity measurement is completed.

As the Table 1 shown, the average temperature in machine shop is $15.96^{\circ} \mathrm{C}$, while the national standard comfortable temperatures for production workshop staves are in the range of $17-22^{\circ} \mathrm{C}$ [2], so, when the staff working in this environment will feel a little cold, that will affect the working efficiency; the average relative humidity in machine shop is $29.82 \mathrm{RH}$, national standard comfort relative humidity is of $40 \%-60 \%$, it is clear that the shop is in the low air humidity environment and people will feel hot at low temperatures and low air humidity; the mean flow velocity in machine shop is $0.015 \mathrm{~m} / \mathrm{s}$, lower than the national standard comfort air velocity of $0.3 \mathrm{~m} / \mathrm{s}$, while the staves will feel the airflow without smooth in the environment, seriously affecting the health and safety of operations.

However, the micro-climate temperature, humidity and air velocity is the mutual influence and mutual restriction. Through the relevant literature and data access, when the flow velocity is under $0.6 \mathrm{~m} / \mathrm{s}$, the air flow velocity decreasing by $0.1 \mathrm{~m} / \mathrm{s}$, equivalent to the temperature rise $0.3^{\circ} \mathrm{C}[2]$, while the speed of the airflow is $0.015 \mathrm{~m} / \mathrm{s}$, decreased $0.285 \mathrm{~m} / \mathrm{s}$ from the GB comfortable air velocity data, equiva- lent to raising the temperature by $0.855^{\circ} \mathrm{C}$ in the workshop, then the workshop temperature reached $16.815^{\circ} \mathrm{C}$, achieving the comfortable standard. In contrast, low temperatures can also increase the air speed and relative humidity, and it will achieve the national standard with the interaction. Of course, this is a paradigm shift theoretical, in practice, any kind of non-compliance of the micro-climate factors will affect the health and productivity. Therefore, a reasonable heating and ventilation is crucial to create a good and comfortable working environment.

\section{ANALYSIS OF WORKSHOP LIGHTING ENVIRON- MENT}

\section{Overview of the Lighting Environment}

Enterprises commonly used natural lighting, artificial lighting and hybrid lighting. The improvement of the lighting environment not only reduces the visual fatigue, but also improves the speed and accuracy of work and reduces the error rate, increases the yield and quality. This section will focus on the study of natural lighting and mixed lighting in the gear machine shop, measure and analysis the basic parameters of lighting to put forward to the improvement program. 
Table 2. Natural light of faces (Unit: lx).

\begin{tabular}{|c|c|c|c|c|c|c|c|c|c|c|}
\hline Measurement Points & 1 & 2 & 3 & 4 & 5 & 6 & 7 & 8 & 9 & 10 \\
\hline Natural light & 203 & 212 & 183 & 204 & 327 & 261 & 331 & 307 & 227 & 177 \\
\hline
\end{tabular}

Table 3. Mixed lighting illumination values (Unit: lx).

\begin{tabular}{|c|c|c|c|c|c|c|c|c|}
\hline Measurement Points & 1 & 2 & 3 & 4 & 5 & 6 & 7 & 8 \\
\hline Mixed lighting & 341 & 233 & 321 & 227 & 407 & 329 & 347 & 293 \\
\hline
\end{tabular}

Table 4. Uniformity of natural light and mixed lighting (Unit: lx).

\begin{tabular}{|c|c|c|c|c|}
\hline & $\mathbf{E}_{\mathbf{1}}$ & $\mathbf{E}_{\mathbf{2}}$ & $\mathbf{E}_{\mathbf{3}}$ & $\mathbf{A}_{\mathbf{u}}$ \\
\hline \hline Natural light & 331 & 177 & 243.2 & 0.36 And 0.24 \\
\hline Mixed lighting & 492 & 227 & 332.1 & 0.48 And 0.32 \\
\hline
\end{tabular}

Table 5. Table local lighting in inspection process (Unit: lx).

\begin{tabular}{|c|c|c|c|c|c|c|c|c|c|c|}
\hline Measurement Points & 1 & 2 & 3 & 4 & 5 & 6 & 7 & 8 & 9 & 10 \\
\hline Local lighting & 280 & 294 & 310 & 300 & 279 & 303 & 276 & 280 & 241 & 248 \\
\hline
\end{tabular}

\section{Status and Improvement of the Lighting Environment}

Through on-site observation of the environment, we uniformly select ten machines within shop tools, select a point on each machine face, using TES-1334 Light Meter to measure the illumination values and obtain the natural light data for each face as shown in Table 2.

In practice, the natural light amount may not meet the lighting for work, and then you need to add artificial lighting. Through on-site investigation, most of lathes in company's machine shop have adopted mixed lighting, so selected ten machines, and take each machine face as a test point, measured obtaining illumination values shown in Table 3 .

As seen from Table $\mathbf{2}$ and $\mathbf{3}$, the average illumination of natural light is $243.21 x$, the average illumination of mixed lighting is $332.11 \mathrm{x}$, literatures shows that the standard illumination value is $3001 \mathrm{x}$ with the machining tolerances greater than or equal to $0.1 \mathrm{~mm}$ [2]. Therefore, for this gear machine shop, the mixed light intensity can reach the production requirement, but prolonged use the mixed light will increase the investment costs.

Conjunction with Table $\mathbf{2}$ and $\mathbf{3}$, and apply the uniformity formula (1), we obtained the overall illumination uniformity further in the gear machine shop, the calculated results are shown in Table 4.

$A_{i<}=\left(\frac{g_{1} g_{2}}{E_{3}}\right.$ And $\left.\frac{g_{3} E_{2}}{E_{1}}\right)<\frac{1}{3}$

( $E_{1}$ for maximum illumination, $E_{2}$ for minimum illumination, $E_{3}$ for averages illumination, $A_{u}$ for uniformity)

As show in Table 4, natural lighting uniformity and mixed lighting uniformity are not completely less than $1 / 3$, does not meet the national standard, so the illumination uniformity in workshop needs to be improved.

(1) Under the natural lighting, shop windows and skylights positions should be adjusted appropriate, to add more natural light.

(2) For mixed lighting, it is necessary for the part of the table to increase artificial lighting, to improve the illumination uniformity.

(3) Provide for special brightness for certain special areas and special operations.

(4) Selecting the tone that can make employees, machinery, equipment, etc. and showing the natural qualities of the light source.

(5) The machine shop should select suitable equipment and ground color, enhancing the clean and comfortable feeling.

In the production process technology, the lighting condition of inspection process is the most rigorous, so it will take the lighting environment of inspection process as the focus. Through on-site observation, the test bench is a rectangular test machine, and the effective working area is of about $30 \mathrm{~cm} \times 40 \mathrm{~cm}$, the light source with mixed lighting mainly for the artificial lighting and the lamps and lanterns are ordinary incandescent lamps, which the height is about $35 \mathrm{~cm}$. Therefore, uniformly selecting 10 test points on the work surface, and using TES-1334 illuminometer to measure the illumination for each measuring point, respectively shown in Table 5.

Table 5 shows that the maximum illumination value $E_{1}$ is $3101 x$, the minimum illumination value $E_{2}$ is $2411 x$, the average illumination value $\mathrm{E}_{3}$ is $281 \mathrm{~lx}$. Through the literatures, workshop inspection work table with a height of about $75 \mathrm{~cm}$, 
Table 6. Illumination uniformity in inspection process (Unit: lx).

\begin{tabular}{|c|c|c|c|c|}
\hline & $\mathbf{E}_{\mathbf{1}}$ & $\mathbf{E}_{\mathbf{2}}$ & $\mathbf{E}_{\mathbf{3}}$ & $\mathbf{A}_{\mathbf{u}}$ \\
\hline \hline Local lighting & 310 & 241 & 281 & 0.103 And 0.142 \\
\hline
\end{tabular}

Table 7. Data of noise measuring point (Unit: $\mathbf{d B}$ ).

\begin{tabular}{|c|c|c|c|c|c|c|c|c|}
\hline Sound level range & $55 \sim 60$ & $60 \sim 65$ & $65 \sim 70$ & $70 \sim 75$ & $75 \sim 80$ & $80 \sim 85$ & $85 \sim 90$ & $90 \sim$ \\
\hline Occurrences number & 0 & 0 & 62 & 226 & 259 & 47 & 6 & 0 \\
\hline Occurrence probability & 0 & 0 & $10.3 \%$ & $37.7 \%$ & $43.2 \%$ & $7.8 \%$ & $1 \%$ & 0 \\
\hline
\end{tabular}

Table 8. Noise measuring data collection (Unit: $\mathrm{dB}$ ).

\begin{tabular}{|c|c|c|c|c|c|c|c|c|}
\hline Sound level range & $>55$ & $>60$ & $>65$ & $>70$ & $>75$ & $>80$ & $>85$ & $>90$ \\
\hline Occurrence probability & 100 & 100 & 100 & $89.7 \%$ & $52 \%$ & $8.8 \%$ & $1 \%$ & 0 \\
\hline
\end{tabular}

the illumination standard value is 3001x [2], so the lighting environment of inspection work in the gear machine shop is not reach the standard, and then calculate the illumination uniformity to analysis by the formula (2), the results are shown in Table 6.

$$
A_{\mathrm{ic}}=\left(\frac{E_{1} E_{2}}{E_{3}} \text { And } \frac{E_{2} E_{2}}{E_{1}}\right)<\frac{1}{11}
$$

From Table 6, the illumination uniformity of the working table is not less than $10 \%$, so the table is of uneven illumination. In the inspection process, the eyes are closed from the work pieces, and the distance for observing the indicator is less than $20 \mathrm{~cm}$. Combined the lighting environment with the average illumination value $2811 \mathrm{x}$, it is likely to cause workers visual fatigue, thus affecting the efficiency of the inspection process. Therefore, using metal halide lamps instead of ordinary white fluorescent or incandescent illumination to improve the lighting tools, because of its high value, heat a small, soft light, high color rendering index and low cost, so that the lighting effects is improved in the inspection environment [3].

\section{ANALYSIS OF WORKSHOP NOISE}

\section{Noise Environment Overview}

Noise refers to all the sound that hinders people life and work, or voices that make people feel tired. This section will take the noise generated by gear machine shop as the study, and analysis of the main sources of noise, sound pressure and the control noise.

\section{Status and Improvement of the Noise Environment}

The noise source in gear machining workshop has the following aspects: mechanical friction in lathe, grinding, milling process, the vibration formed by the mechanical transmission; the noise formed by the workshop workers manual work; transportations cause the noise when the work pieces are transferring, etc. In a noisy environment, workers are of inattention, and it will lead to prolonged reaction, in- creased error and directly affect the efficiency and safety of operations.

In order to ensure the accuracy of measurement and minimize the error, choose ten measurement points that take the human ear height as a criterion, measured 60 times with the TES-1350A noise meter and divide to the range of the sound level according to the statistics of measurement results, then statistics the occurring times with 600 measured values within the scope of the sound level and calculate the probability, the results shown in Table 7 and $\mathbf{8}$ below.

According to the data in Table 7, we get the noise level statistical histogram of workshop shown in Fig. (1).

Fig. (1) shows that the sound level statistical curve assumes a shape with high in the middle, low profile on both sides, it accord with the characteristics of the normal distribution, then it can be drawn from the statistical noise sound level according to the statistical calculation formula (3) [4].

$$
L_{\mathrm{sq}}=L_{5 a}+\frac{d^{2}}{60}
$$

$d=L_{10}-L_{10}$

According to the data in Table 8 , using the difference value method can obtain the data with $\mathrm{L}_{50}, \mathrm{~L}_{10}$ and $\mathrm{L}_{90}$.

$$
\begin{gathered}
L_{5 \mathrm{a}}=\frac{52 \%-50 \%}{52 \%-8.8 \%} \times 5+75=75.2 \mathrm{~dB} \\
L_{10}=\frac{52 \%-10 \%}{52 \%-8,8 \%} \times 5+75=79.9 d B \\
L_{9 \mathrm{n}}=\frac{100 \%-90 \%}{100 \%-89.7 \%} \times 5+65=69.9 \mathrm{~dB} \\
L_{\mathrm{sq}}=76.9 \mathrm{~d} B
\end{gathered}
$$

According to China's regulations, job site personnel continuous exposure to noise 8 hours a day, the noise level 


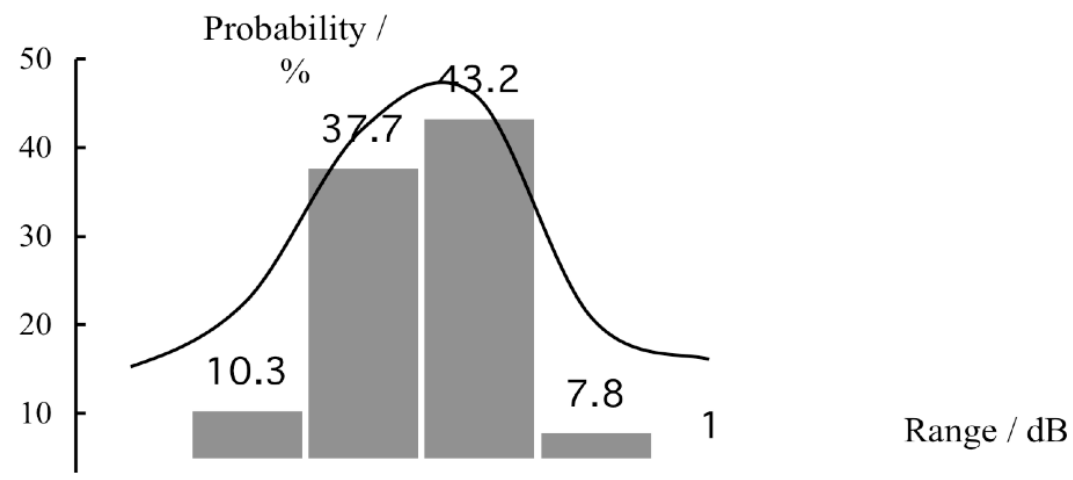

Fig. (1). Noise level histogram.

should be limited to $85 \mathrm{~dB}$. Through the on-site investigation of gear processing, the operating time is 8 hours per day, so the noise level should be less than $85 \mathrm{~dB}$. As formula (4) shown, the average sound level statistics of noise in gear machine shop is $76.9 \mathrm{~dB}$, does not exceed the national standards [2]. Therefore, it is not necessary to optimize the noise of the machine and workshop environment better.

\section{CONCLUSION}

At present, the existing studies on specific man-machine workshop made a thorough theoretical analysis of the environmental factors, climate environment, lighting and noise environment is the main factors that influence the efficiency of the production workshop employee's health, but this is only confined to the local environment and special area Based on the basic theory of human factors engineering and human environment, in order to improve the workshop environment quality, and improve the staff work comfort and work efficiency for research purposes, measured and analyzed the basic parameters of the micro-climate environments, lighting environments and noise environments in overall workshop and specific process, and evaluated the merits of the site environment in reference to the national standard parameter values, verify the objectivity and correctness of the theoretical research. Through the contrastive analysis of the measured data with the national standard parameters, noise environment in line with the international standard, while the micro-climate and lighting conditions do not meet the requirements, and thus putting forward to the optimization program. Combined with the previous research both at home and abroad and the theory of this paper prove the feasibility of improving scheme further, providing a healthy and safe working environment for staves.

\section{CONFLICT OF INTEREST}

The authors confirm that this article content has no conflict of interest.

\section{ACKNOWLEDGEMENTS}

This study was supported by the Foundation for Science and Technology Program of Ministry of Housing and UrbanRural Development of the People's Republic, China (Grant No. 2014-R1-018), by the Natural Science Foundation of Inner Mongolia, China (Grant No. 2014BS0707), by the Scientific Research Foundation of the Higher Education Institutions of Inner Mongolia, China (Grant No. NJZY14076), by the Scientific Research Key Program of Inner Mongolia University of Technology (Grant No. ZD201211), by the Scientific Research Program of Inner Mongolia University of Technology (Grant No. X201213), by the teaching reform project of Inner Mongolia University of Technology (Grant No. 2011003).

\section{REFERENCES}

[1] Wang Yu Lei, Wang Qianqian. Human Factors Engineering Applied Research Workshop in .Business Business Forum .2013

[2] Guo volts, the money they save three. Human Factors Engineering. Machinery Industry Press .2007

[3] Xun Li, Sang Bong Yoo.Integrity validation in semantic engineering design environment. Computers in Industry.2011,62

[4] LeMay modern enterprise human factors engineering and theoretical analysis should study. North University master's degree thesis .2012

(C) Guang-Jun and Hao-Dong; Licensee Bentham Open.

This is an open access article licensed under the terms of the Creative Commons Attribution Non-Commercial License (http://creativecommons.org/licenses/by-nc/3.0/) which permits unrestricted, non-commercial use, distribution and reproduction in any medium, provided the work is properly cited. 